\title{
A internação compulsória como estratégia de governamentalização de adolescentes usuários de drogas
}

Neuza Maria de Fátima Guareschi. Universidade Federal do Rio Grande do Sul.

Lutiane de Lara. Centro Universitário Metodista.

Daniel Dall'Igna Ecker. Universidade Federal do Rio Grande do Sul.

\section{Resumo}

Este artigo tem como objetivo problematizar a internação compulsória de adolescentes usuários de drogas em um serviço de saúde mental de Porto Alegre/RS a partir da noção de Biopolítica, proposta por Michel Foucault. Assim, primeiramente, descrevemos o processo de internação compulsória e os percursos dos jovens no serviço para depois avançarmos na análise da internação compulsória como uma estratégia de governamentalização da vida. Esta análise leva para a desnaturalização das ações contemporâneas do Estado direcionadas aos adolescentes usuários de drogas e aos atravessamentos dos interesses de mercado que operam no contexto dessa política. Por fim, apontamos a suspensão dos elementos universais que permeiam a temática das drogas como possibilidade de ruptura dos padrões de cuidado até então colocados no campo da saúde.

Palavras-chave: internação compulsória; adolescência; droga; Foucault, Michel, 1926-1984.

\begin{abstract}
The compulsory hospitalization as a governmentalization strategy for the adolescent drug users. This article aims to discuss the compulsory hospitalization of adolescent drug users in a mental health service in the city of Porto Alegre/RS from the notion of Bio-politics, proposed by Michel Foucault. So, first, we describe the process of compulsory hospitalization and the passages of young people in the service, and thus we move to the analysis of compulsory hospitalization as a strategy of governmentalization of life. This analysis leads to the denaturalization of contemporary state actions directed to adolescent's drug users and the crossings market interests operating in the context of this policy. Finally, we point to the suspension of the universal elements that permeate the theme of drugs as a possibility to break off the standards of care placed in the health field.
\end{abstract}

Keywords: compulsory hospitalization; adolescents; drugs; Foucault, Michel, 1926-1984.

\section{Resumen}

El internamiento como estrategia de gobernamentalización de adolescentes consumidores de drogas. Ese artículo tiene como objetivo problematizar el internamiento forzado de adolescentes consumidores de drogas en un servicio de salud mental de Porto Alegre/RS a partir de la noción de la Biopolítica, propuesta por Michel Foucault. Así, primero, describimos el proceso de internamiento forzado y el camino de los jóvenes en el servicio investigado como un fenómeno inherente al campo de la problemática de las racionalidades del gobierno de las conductas. Análisis que desnaturaliza las acciones de hoy día del Estado dirigidas a los adolescentes consumidores de drogas al discutir los intereses del mercado que operan en el contexto de esa política. Por último, apuntamos la suspensión de los elementos universales que permean la temática como posibilidad de rotura de los patrones de cuidado hasta el momento colocados en el campo.

Palabras clave: internamiento forzado; adolescencia; droga; Foucault, Michel, 1926-1984. 
Este artigo deriva da Pesquisa "A Relação entre justiça e saúde mental no contexto dos adolescentes usuários de drogas" ${ }^{1}$, desenvolvida no Grupo de Pesquisa Estudos Culturais e Modos de Subjetivação junto ao Programa de Pós-Graduação em Psicologia Social e Institucional da UFRGS. Neste texto, objetivamos problematizar os processos de internação compulsória de adolescentes usuários de drogas que acessaram um serviço de saúde mental de Porto Alegre/RS², Brasil, a partir do conceito de Biopolítica, proposta por Michel Foucault (2004; 2005). O intuito de analisar a relação entre ações da área da justiça e da saúde mental visa discutir sobre os modos como operam e se legitimam os processos de internação compulsória de jovens usuários de drogas, os quais apenas se tornam possíveis mediante encaminhamentos realizados na integração entre familiares, profissionais da saúde e o sistema judiciário.

Entendida como um recurso que deveria ser a última estratégia de cuidado, a internação compulsória foi, principalmente no ano de 2013 , alvo de discussões e de disputa de interesses. A questão emerge tendo em vista as consequências da possível aprovação do Projeto de Lei $n^{0}$ 7663/2010 do Deputado Federal Osmar Terra que, além de outras providências, altera as disposições referentes à internação compulsória, priorizando a institucionalização psiquiátrica em detrimento a outros tipos de intervenções (Câmara dos Deputados, 2014). O Projeto de Lei, que no momento aguarda retorno do Senado Federal, fez emergir no campo psi discussões prioritariamente pautadas pelo Conselho Federal de Psicologia (CFP). Os debates originaram um Parecer de 51 páginas escrito por representantes do CFP que reconhecem a complexidade da temática do uso de drogas e, enquanto categoria, manifestam opinião contrária à aprovação do PL no 7663/2010, considerando-o uma ameaça aos direitos civis e um equívoco diante das problemáticas que envolvem o uso de drogas no Brasil (Conselho Federal de Psicologia, 2013).

Apesar dos acirrados debates de 2013, a internação compulsória constitui-se como uma ação executada pelos meios jurídicos mesmo anteriormente ao Projeto de Lei de 2010. Essa realidade já era possível de ser visualizada quando finalizamos a primeira etapa desta pesquisa no final do ano de 2011. Assim, a partir do ano de 2012 e no decorrer de 2013 adentramos na segunda etapa do estudo analisando as informações produzidas na primeira etapa da pesquisa a partir do enfoque da governamentalização da vida (Foucault, 2004) como uma ferramenta teórica para colocar o campo de análise em movimento.
A noção de Biopolítica é retomada por Michel Foucault, no curso ministrado no Collège de France de 1979, Nascimento da Biopolítica, como tecnologia de poder central na análise da construção e desdobramentos do capitalismo na sociedade contemporânea (Foucault, 2004). Nele, o autor dá sequência a análise dos modos de governamentalidade liberal, pensando sobre as racionalidades políticas nas quais foram inseridas as problemáticas específicas da vida e da população. A Biopolítica, para o autor, se insere como uma tecnologia de poder que investe na vida almejando buscar a eficácia máxima da ação do governo mediante a intervenção na população (Foucault, 2004).

Para avançarmos na análise Biopolítica da internação compulsória elegemos fugir dos universais que explicam a prática governamental dessa população. Dessa forma, tomamos os universais que compõem nosso tema de pesquisa e supomos que não existam para que não sejamos tomados pelas naturalizações que os constituem. Esse método, semelhante ao que o autor propõe quando analisa os discursos sobre a loucura, consiste em dizer: "(...) suponhamos que a loucura não exista. Qual é, por conseguinte, a história que podemos fazer desses diferentes acontecimentos, dessas diferentes práticas que, aparentemente, se pautam por esse suposto algo que é a loucura?" (Foucault, 2004, p.5).

Assim, tomamos o contexto de adolescentes internados por medida compulsória devido a transtorno mental associado ao uso de drogas, abrindo mão de pensá-los a partir de discursos universalizantes presentes em, por exemplo: 1) Na ideia de adolescência como uma suposta fase da vida em que os sujeitos, de forma generalizada, teriam ações inconsequentes e por isso necessitariam ser vigiados e controlados; 2) Entendimento do uso de drogas como um ato criminoso, uma ação contra a própria vida ou contra a harmonia social; 3) Pobreza, falta de higiene ou habitar a rua como modos de vida a serem combatidos, visto que estariam em um patamar inferior a outros modelos de existência pautados pelo consumo, higienismo e pela propriedade particular; 4) Ideia de loucura como algo real, que precisaria ser medicada e controlada; 5) Noção de saúde mental como diretamente associada a quem tem um determinado estilo de vida, pautado pela lógica da família nuclear, que vive em ambientes privados, que estão disciplinados para o trabalho, consomem frequentemente e se conformam com o modo como o mundo está atualmente organizado.

No processo de pesquisa buscamos realizar o exercício para que esses universais deixem de orientar 
nossa percepção sobre o campo de estudo. Ao mesmo tempo julgamos necessário não negar que eles se atravessam nos processos de internação e nas práticas de governamentalidade que são propostas para os jovens aqui em questão. Assim, tentamos partir da prática governamental e não dos a priori que constituem as práticas de cuidado, tomando como analisador as reflexões e raciocínios veiculados para compreendermos como a história os modula, os modifica e os qualifica como verdade (Foucault, 2004).

Assim, a seguir, descreveremos os passos da pesquisa que nos levaram a questão das racionalidades de governo, inicialmente detalhando o processo de internação compulsória e os percursos dos jovens no serviço. Após, adentrando na noção de Biopolítica, descrevendo como a questão teórica de Foucault nos conduz na segunda etapa do estudo, visando ampliar nossa visão sobre os materiais analisados.

\section{Percursos iniciais da pesquisa}

A internação compulsória é uma medida solicitada por familiares, serviços de saúde, pessoas próximas ao usuário, ou via outros meios, que aciona o jurídico visando tornar ágil e efetivo o acesso do sujeito a algum serviço de saúde. A compulsoriedade nos encaminhamentos tem sido evidenciada em pesquisas da Psicologia como uma medida frequente no contexto de usuários de drogas (Scisleski \& Maraschin, 2008).

Na Lei 10.216 de 6 de abril de 2001, que surge junto aos movimentos da Reforma Psiquiátrica, a internação compulsória já está prevista como uma ação que visa proteger e garantir os direitos das pessoas portadoras de transtornos mentais, especialmente, o direito à proteção da vida (Brasil, 2001). No que se refere à internação, a Lei institui que: "Art. 4ํㅗ $\mathrm{A}$ internação, em qualquer de suas modalidades, só será indicada quando os recursos extra-hospitalares se mostrarem insuficientes. $§ 1^{\circ} \mathrm{O}$ tratamento visará, como finalidade permanente, a reinserção social do paciente em seu meio" (Brasil, 2001).

Ao ser proposta a internação como uma medida indicada apenas quando os recursos extra-hospitalares fossem ineficazes, nos surpreendemos aos nos depararmos com os dados da primeira etapa de estudo que foram obtidos no serviço de saúde mental aqui colocado em questão (Tabela 1).

Nesse levantamento pudemos visualizar, pela análise do cadastro de entrada no serviço, o número de ingressos em um Hospital Psiquiátrico ${ }^{3}$ durante o período de três anos. Como evidenciamos através dos resultados
Tabela 1. Número de Ingressos no Hospital Psiquiátrico São Pedro e no Centro Integrado de Atenção Psicossocial - Infância e Adolescência (CIAPS) Durante o Período de Três Anos.

\begin{tabular}{lcccc}
\hline & $\begin{array}{c}\text { Hospital } \\
\text { Psiquiátrico }^{\text {a }}\end{array}$ & $\begin{array}{c}\text { Unidade } \\
\text { CIAPS } \\
\text { (total) }^{\mathrm{b}}\end{array}$ & $\begin{array}{c}\text { Unidade } \\
\text { CIAPS } \\
\text { (medida }_{\text {judicial) }}\end{array}$ & $\begin{array}{c}\text { Unidade } \\
\text { CIAPS } \\
\text { (medida }_{\text {judicial) }}\end{array}$ \\
\hline 2008.2 & 809 & 134 & 49 & 38 \\
2009 & 1386 & 280 & 57 & 33 \\
2010 & 1422 & 272 & 41 & 26 \\
2011.2 & 712 & 148 & 23 & 10 \\
Total (3 anos) & 4329 & 834 & 170 & 107 \\
\hline
\end{tabular}

Fonte: Unidade de triagem do Hospital Psiquiátrico São Pedro, Porto Alegre,

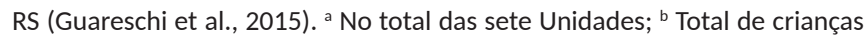
e adolescentes; ' Por medida judicial, crianças e adolescentes; ${ }^{\mathrm{d}}$ Por medida judicial, adolescentes com diagnóstico de uso de drogas associado a transtorno mental.

visíveis na Tabela 1, nos três anos estudados, a unidade de internação de crianças e adolescentes obteve 834 internações. Dessas 834 internações, 170 foram devido à medida judicial. Assim, em três anos, do total de internações da unidade, $20 \%$ foram via medida judicial. Esse número denuncia um dado significativo no que se refere à relação entre saúde e justiça no campo da saúde mental. Como o nosso Projeto de Pesquisa delimita a discussão com foco na adolescência e uso de drogas, selecionamos o dado da última coluna da tabela, à direita, que nos mostra que nesses três anos de análise, das 834 internações, 107 foram de adolescentes com diagnóstico de uso de drogas associado a algum transtorno mental. Todas essas 107 internações ocorreram devido à medida judicial (Guareschi et al., 2015).

No intuito de conhecer o processo de internação compulsória desses jovens, saímos do setor de triagem e nos aproximamos da unidade de internação, através do contato com os prontuários desses adolescentes. Os prontuários ficam arquivados na instituição sempre que cada jovem obtém alta e neles são centralizadas todas as informações que se referem ao sujeito atendido. Quando chegam ao Hospital, todos os usuários passam pelo processo de triagem no qual será definida a unidade que serão encaminhados. Na triagem é feita a avaliação dos adolescentes por um psiquiatra, acompanhado de um assistente social quando disponível, que verifica a necessidade ou não de internação. Se indicada a internação, ele deve estabelecer um diagnóstico de pré-internação (passível de modificação após ingresso no serviço) ou se orientar a partir dos diagnósticos estabelecidos nos encaminhamentos trazidos pelos adolescentes que, de forma geral, se baseiam nos critérios da Classificação Internacional de Doenças - CID-10 (Organização 
Mundial da Saúde [OMS], 2003). Para acessar qualquer unidade do local é obrigatório que na avaliação conste um diagnóstico visto que nas orientações do Estado se justifica a internação mediante patologia inscrita na CID. O diagnóstico pela CID serviria para afirmar a internação enquanto necessária e legítima.

Após indicação de internação é feito um registro do usuário no livro de baixa ${ }^{4}$. Em seguida a esse cadastro, o usuário recebe uma pasta, na qual ficam centralizadas todas as informações referentes a ele. Todos os documentos trazidos pelos usuários ou seus responsáveis fazem parte da composição inicial dos prontuários. Ao obter a alta da instituição, o sujeito terá seu prontuário arquivado em uma sala, no próprio Hospital, em que se centralizam os prontuários dos usuários das sete unidades (Guareschi et al., 2015).

Ao nos aproximarmos dos prontuários dos jovens internados na unidade de crianças e adolescentes, tivemos a oportunidade de acessar, efetuar a leitura e análise de todos os prontuários dos jovens que foram internados no ano de 2010, via medida judicial, devido transtorno mental associado ao uso de drogas. Totalizamos a análise de 33 prontuários ao longo da primeira etapa da pesquisa. Os prontuários incluem a centralização de documentos referentes ao jovem desde documentos jurídicos, exames de saúde, receitas de medicação, encaminhamentos dos serviços de saúde a formulários em formato padrão do Hospital, são eles: 1) Ficha organizadora; 2) Cadastro individual; 3) Lista de problemas; 4) Plano de tratamento individual; 5) Evolução; 6) Guia de encaminhamento de egresso/nota de alta (Guareschi et al., 2015). Elegemos acessar e analisar os prontuários do ano de 2010, devido a grande repercussão na mídia que a internação obteve nesse período, através das campanhas de combate às drogas, especialmente sobre o uso do crack (Guerra ao crack, 2009).

Pela análise dos prontuários na primeira etapa da pesquisa destacamos que o diagnóstico de transtorno mental nem sempre está presente na vida do jovem, enquanto uma categoria que o classificava, até ele acessar o serviço aqui analisado. A ordem judicial, documento obrigatório nas internações compulsórias, será a primeira via de acesso ao diagnóstico para aqueles que anteriormente não o possuíam. Na ordem judicial, o juiz solicita que o serviço faça uma avaliação médica do adolescente, a qual ocorre na unidade de triagem, como descrito anteriormente. Assim, o juiz elabora esse documento visando à condução do jovem para o serviço de saúde devido a uma suposta, mas ainda não "confirmada", necessidade de internação. De forma geral, as justificativas que embasam a ordem judicial se baseiam em relatos dos profissionais ou de familiares que estavam em contato com o adolescente antes do atendimento no Hospital. São esses discursos dos outros, profissionais de saúde ou familiares, que vão definir a necessidade de avaliação do jovem.

De forma geral, as ordens judiciais se utilizam da descrição e da exaltação do comportamento e da conduta do adolescente para embasar suas justificativas de encaminhamento como, por exemplo: eles criam situações de conflito, não obedecem às regras, não obedecem às determinações médicas e utilizam drogas. Mesmo sendo um pedido de avaliação, a ordem judicial tem características de medida de segurança. Essa medida surge como forma, em alguns casos, de "segregação de quem expõe a perigo a integridade de seus familiares e compromete a segurança da sociedade" [sic]. Para efetivar a ordem judicial o juiz sugere e autoriza que os profissionais do serviço de saúde utilizem "força policial para fiel cumprimento da medida" [sic]. São esses discursos, colocados em documentos impressos, que garantem o encaminhamento do jovem para o serviço de internação aqui estudado (Guareschi et al., 2015).

Como já relatamos, a internação em todas suas modalidades é uma medida prevista na Lei 10.2016 que deveria ser indicada apenas quando os recursos extra-hospitalares se mostram insuficientes (Brasil, 2001). O que estudos indicam é que, na prática, ela tem servido para dar conta da falta de serviços de atenção primária ou de promoção de saúde no campo do uso de drogas, como estratégia para afastar o jovem "problema" temporariamente ou pela própria dificuldade do Estado aceitar outros modos de vida como, por exemplo, dos moradores de rua, que possuem outras formas de habitar a cidade e de se relacionarem consigo (Reis, 2012). Mediante a análise dos 33 prontuários, percebemos que muitos desses casos acabam por chegar ao serviço via medida judicial como forma de agilizar uma ação mais eficaz do sistema Estatal sobre eles.

$\mathrm{Na}$ análise dos prontuários evidenciamos, por exemplo, que na avaliação psiquiátrica da triagem o relato do entendimento sobre o jovem é muito sucinto. Geralmente, o foco da descrição realizada pelo profissional está associado às ações e comportamentos do adolescente que são coletados nas entrevistas ou nos documentos que vieram junto ao encaminhamento. A partir dessa descrição previamente estabelecida pelos documentos, e de uma entrevista superficialmente 
desenvolvida, resultará a afirmativa que justificará a internação com poucas palavras como, por exemplo, as a seguir: "uso de drogas" [sic], "agressividade" [sic], "agitação" [sic], "realização de furtos e assaltos" [sic], "descrição de situações de risco" [sic], "exposição moral" [sic] e "riscos para si e terceiros" [sic].

Além dessas descrições, a avaliação psiquiátrica sempre enuncia a necessidade de revisão dos medicamentos e se utiliza das categorias diagnósticas da CID para classificar a suposta "doença" do adolescente, que foi diagnosticada em 15 minutos de atendimento ou pelos documentos que vieram em anexo com o jovem. $\mathrm{Na}$ análise dessas classificações nos prontuários estudados nota-se que as doenças estabelecidas para os 33 jovens se situavam entre a CID F10 e o F19 as quais classificam todos os transtornos mentais associados ao uso de drogas (OMS, 2003).

É importante destacarmos que no processo de análise dos materiais, na primeira etapa da pesquisa, percebemos que a avaliação psiquiátrica é algo mutável e incerta. O jovem é inserido no serviço sob justificativa de, por exemplo, possuir Transtorno Bipolar associado ao uso de drogas e obtêm alta do serviço classificado com Transtorno de Conduta associado ao uso de drogas. Ao conversarmos com profissionais do serviço sobre essa questão, eles nos relatam que o diagnóstico não é uma questão central no "tratamento", pois muitas vezes os jovens estão em situação de rua, sem ter acesso à higiene ou alimentação, e essas se tornam as maiores justificativas da internação. Ele é internado sem real implicação do profissional com a existência ou não daquela psicopatologia, mas sim, pautado por sua preocupação em acolher o adolescente.

Pesquisadoras na área da Psicologia Social discutem que o risco de morte presente no cotidiano, justificado pelo argumento da vulnerabilidade social, são algumas das principais justificativas que fazem emergir intervenções do judiciário sobre a vida de jovens, especialmente os que estão em situações econômicas desfavorecidas, moradores de rua e usuários de drogas. A questão do controle sobre a vida e manutenção de um determinado modo de organizar a cidade e o cotidiano das pessoas faz evidenciar, através dessa relação entre saúde e justiça, todo um aparato de saberes, profissionais e serviços, que atuam em conjunto e acabam por incluir a vida dos jovens em mecanismos de gestão do Estado (Scisleski et al. 2012).

$\mathrm{Na}$ análise dos prontuários, percebemos que o diagnóstico é a porta de entrada do jovem para todo um sistema operacional de gerenciamento de suas existências. Na avaliação psiquiátrica da triagem, no momento em que os comportamentos dos adolescentes se associam ao uso de substâncias e a uma categoria diagnóstica, se passa a marcar no real algo que a priori não existia: uma doença (psicopatologia). Essa doença faz o jovem acessar o serviço e ser submetido a todo um processo de "tratamento" dentro da internação.

Ao analisarmos os documentos que são preenchidos ao longo da internação, especialmente o "Diário de tratamento", caderno presente no cotidiano do serviço no qual cada profissional preenche diariamente relatos de seu contato com o adolescente, percebemos que o diagnóstico será a primeira referência do profissional para se relacionar com aquele jovem que acessa à internação. Dessa forma, o que notamos nos relatos dos Diários é que o adolescente passa a ser compreendido através da comparação de seu comportamento atual com o descrito anteriormente na avaliação de triagem como, por exemplo, "está menos agressivo" [sic] ou "já respeita mais as regras" [sic]. Nesse sentido, evidenciamos que a internação compulsória passa a construir o "jovem doente" a partir do modo como os documentos vão sendo preenchidos, tendo como principal base os argumentos dos profissionais que se colocam a escrevê-los. Foucault descreve esse processo, a partir de sua discussão sobre a construção das disciplinas do conhecimento, como um efeito discursivo (Foucault, 1984), na medida em que aquilo que se diz sobre um objeto e/ou sujeito acaba por produzi-lo e não somente representá-lo.

Assim, ainda que o diagnóstico não seja o motivo pelo qual o adolescente é acolhido, ele passa a legitimar modos de existência através de discursos com viés patologizante que começam a ser compostos sobre o jovem a partir de sua entrada na instituição e permanência no processo de "tratamento". Muitos dos adolescentes internados advêm de contextos de miséria, onde os direitos básicos previstos pelo Estatuto da Criança e do Adolescente (Lei no 8.069, de 13 de julho de 1990) estão negligenciados. Educação, saúde, moradia, alimentação, transporte, entre outros, não são temas próximos de suas realidades no que se refere ao acesso a esses direitos previstos também em Constituição Federal (Constituição da República Federativa do Brasil de 1988).

Outro ponto importante encontrado na primeira etapa da pesquisa é que nos escritos dos Diários de tratamento muitos colocam em evidência que o uso de drogas nem sempre é problemático na vida dos jovens que acessam a instituição. Encontramos relatos de profissionais 
que descreviam ter conversado com o adolescente e ele expôs que "experimentou crack apenas uma vez" [sic] ou "fumou um cigarro de maconha quando tinha 14 anos" [sic]. Ao conversarmos informalmente com uma das profissionais do serviço ela relata que, semelhante ao descrito anteriormente, em muitos casos o uso de drogas não é problemático na vida dos adolescentes, mas, como eles advêm de contextos de miséria e de violação de direitos, a internação acaba por funcionar como estratégia para permitir que, durante o período na instituição, eles tenham acesso à comida, higiene, moradia fixa e proteção tutelada, por exemplo.

Essa questão nos leva ao último percurso da primeira etapa da pesquisa, na qual analisamos os documentos que compõem a descrição da alta. Os jovens passam pela triagem, são internados durante determinado período e obtêm alta da instituição. A alta seria semeIhante à oficialização de um "tratamento bem sucedido". Nesse documento assinado pelo psiquiatra se justifica o porquê da saída do adolescente e, também, se descreve possíveis proposições de encaminhamentos dentro da rede intersetorial (Guareschi et al., 2015).

Nessa parte do prontuário que, a princípio, define aspectos importantes na atenção à saúde desse jovem em longo prazo, as propostas de cuidado que mais se repetem são: "uso de medicação" [sic] e "encaminhamento para serviço de saúde mental" [sic]. Dos 33 prontuários analisados, 32 dos adolescentes obtiveram alta com indicação de medicação (97\%), 19 foram encaminhados para outros serviços de saúde mental CAPS, CAPS-AD, psiquiatras ou psicólogos (62\%), oito foram encaminhados para fazendas ou comunidades terapêuticas (26\%), quatro indicavam a possibilidade dos adolescentes voltarem a estudar (12\%) e dois sugeriram a busca por cursos profissionalizantes (6\%). Em relação ao número de internações percebe-se que, dos 33 jovens, 23 estão entre a primeira e a segunda internação (74\%) e oito se encontram entre a terceira e sexta (26\%) (Guareschi et al., 2015).

O índice significativo de internações compulsórias, a alta taxa de reinternações e as propostas de encaminhamentos nos fazem colocar em suspensão o processo de internação e a efetividade no que se propõe como algo dado e natural, para entendê-la como um problema a ser pensado. $O$ jovem chega ao serviço advindo de um contexto de miséria, diante disso, a internação compulsória neste serviço analisado não é a realidade primeira de cuidado para jovens oriundos, por exemplo, de outros contextos socioeconômicos. Após o "tratamento" eles saem do serviço na mesma condição de miséria, tendo apenas a medicação, os serviços de saúde mental e as comunidades terapêuticas como seus próximos percursos e projetos de vida. O processo de internação compulsória, junto à categoria diagnóstica que o legitima e é atribuída ao adolescente, passa a administrar o cotidiano de muitos desses jovens no momento em que os declara como sujeitos que necessitariam de um acompanhamento profissional para que possam circular livremente, devido a uma suposta "doença" que estaria presente em seus corpos.

Aragaki (2006) discute que, apesar do diagnóstico de transtorno mental limitar espaços de circulação social dos sujeitos categorizados, há uma exceção. Essa exceção é visualizada pela inclusão deles em matrizes de especialidades da área de saúde mental, ou seja, através da obtenção do diagnóstico o sujeito passa a participar de toda uma gama de serviços que estão ali colocados para atender o portador de transtornos mentais.

São todas essas questões que nos fizeram seguir para a segunda etapa da pesquisa, neste artigo discutida, onde buscamos ferramentas teóricas para ampliar nossa análise sobre o campo de estudo. Os percursos de leitura nos colocam de encontro com as obras de Michel Foucault, especialmente a intitulada Nascimento da Biopolítica (2004). É a partir dessa obra que colocamos em análise a noção proposta pelo autor de Biopolítica pensando sobre a internação compulsória e os efeitos que ela produz nas práticas de cuidado dos jovens internados.

\section{A Internação Compulsória e a Biopolítica}

Michel Foucault, em seu curso ministrado no Collège de France de janeiro a abril de 1979 , retoma o conceito de Biopolítica como uma continuidade às discussões desenvolvidas no curso anterior, principalmente no que se refere ao processo de governamentalização da vida.

O conceito de Biopolítica foi introduzido nas análises pós-estruturalistas por Foucault (2005) em meados da década de 1970 como tecnologia de poder capaz de problematizar os fenômenos do século XX de estatização da vida biológica, em que o nazismo foi a experiência limite. As discussões que envolvem a Biopolítica engendram análises sobre as condições do exercício político no contemporâneo e também nas políticas públicas.

O processo de investimento na vida, tal como descrito por Foucault (2005), configurou uma normalização da vida que juntou uma tecnologia disciplinar a uma tecnologia regulamentadora ou previdenciária, a primeira com o polo no corpo e a segunda com o polo na população. Na modernidade, o humano "é um animal, 
em cuja política, sua vida de ser vivo está em questão" (Foucault, 2007, p. 156), não mais um animal vivo capaz de existência política, como na Polis grega. Como efeito, a modernidade passou a condicionar o exercício político ao fato biológico da existência, ou seja, é em função de nossa existência biológica que exercemos nossa política e é o biológico que entra em questão no debate político.

Ao longo do curso de 1979, Foucault dará sequência à análise das formas de governamentalidade liberal, tratando de descrever as racionalidades políticas nas quais, em seu interior, foram colocadas as problemáticas específicas da população e da vida. É através dessas questões que Foucault adentra no campo da história contemporânea trazendo à tona o papel ambivalente da sociedade em relação às práticas de governo. Produzir liberdades se torna uma estratégia necessária para que o liberalismo econômico, especialmente estabelecido nos séculos XVIII e XIX, possa operar permanentemente. Essa questão coloca a população em uma relação correlativa de produção, a sociedade deixa de se opor ao Estado e passa a ser entendida como necessária para que ele próprio possa existir e operar (Foucault, 2004).

Contemporaneamente, como um processo iniciado pelos neoliberais norte-americanos em meados do século XX, é central o mecanismo que possibilita reinterpretar, em termos econômicos, todo um domínio que até então não se considerava econômico, como a vida das pessoas e as relações que elas estabelecem com os outros. Nesse sentido, o planejamento do futuro, a educação dos filhos, os cuidados com a saúde, o pagamento de previdência privada, etc. passam a ser elementos utilizados para a racionalização cotidiana da vida das comunidades. Trata-se de uma análise econômica das relações que consiste em compreender qual foi o cálculo realizado pelo indivíduo para destinar o recurso escasso a tal fim, e não a outro. A economia, nas sociedades neoliberais, tornou-se a análise de uma atividade, deixando de ser a análise da lógica histórica dos processos; ela é a análise da programação estratégica da atividade dos indivíduos (Foucault, 2004).

O neoliberalismo passa a aplicar a grade de inteligibilidade econômica a âmbitos de comportamentos e condutas que até então não eram considerados ligados ao mercado. A análise econômica passa a ser aplicada nos casamentos, na educação dos filhos, na criminalidade, na imigração, na saúde mental, etc. O neoliberalismo generalizou a forma econômica do mercado na totalidade da comunidade, buscando, assim, uma inversão das relações sociais em relações econômicas. A forma econômica aplicada à conduta dos sujeitos busca aperfeiçoar a ação destes, a fim de racionalizar o cotidiano. O princípio que rege essa forma é o de que a ação dos sujeitos não seja aleatória, devendo sempre responder de maneira sistemática às variáveis que o meio apresenta. Tal racionalização estabelece em cada conduta um fim desejado e, desse modo, busca criar estratégias que racionalizem os recursos existentes para se chegar ao previsto (Foucault, 2004).

As estratégias de regulação Biopolíticas da vida constituem nossa experiência política permeadas por modelos e gerenciamentos da conduta individual e coletiva, de forma que a prática política tende a reproduzir os modelos institucionais de acesso aos direitos e, dessa forma, à estatização da vida e ao aumento do poder do Estado nas dinâmicas da vida. Isso é possível porque, na construção do investimento biopolítico, a norma foi agregada à lei. Assim, a lei funciona cada vez mais como norma e o sistema jurídico tem se integrado gradativamente a aparelhos médicos, psiquiátricos, psicológicos, etc., assumindo funções reguladoras (Foucault, 2007), como na internação compulsória de usuários de drogas realizada conjuntamente por aparatos de saber/poder que unem Estado, Polícia Militar, profissionais da saúde e família.

A reflexão realizada por Foucault (2004) no Nascimento da Biopolítica avança, desta forma, até a construção do neoliberalismo alemão, francês e americano como desdobramentos das críticas existentes em meados do século XX, tanto às políticas de planificação econômica de inspiração keynesianas, quanto aos governos totalitários das primeiras décadas desse século e, inclusive, sobre o próprio liberalismo econômico. Sob a prerrogativa de libertar a economia das injunções estatais, o autor analisa como o neoliberalismo econômico radicaliza/modifica a fórmula de prerrogativa de intervenção estatal sobre o indivíduo. Nela, se expande a lógica econômica aos diferentes âmbitos do tecido social, ou seja, se racionaliza não só a economia, mas a sociedade como um todo. Esta fórmula constitui o Homo oєconomicus como o sujeito manejável da prática governamental, sob o qual não se pode tocar diretamente, mas somente através de modificações nas variáveis do meio (Foucault, 2004).

O neoliberalismo econômico, ao inserir a lógica econômica na organização e intervenção da vida da população, gerou a necessidade de reformulação da instituição jurídica e das regras do direito, que são necessárias em uma sociedade regulada por uma economia competitiva de mercado. A sociedade como lugar de intervenção 
passou a ser atravessada por uma nova ordem, não mais apenas do direito ou da economia, mas econômico-jurídica. Nessa ordem a sociedade se forma nos moldes da empresa e da produção, redefinindo suas instâncias jurídicas a partir de uma economia competitiva de mercado, adotando a postura do "governar menos, para ter eficiência máxima". Trata-se, portanto, de um conjunto de atividades reguladas que apresentam regras e leis no campo das relações de produção (Foucault, 2004).

O neoliberalismo utiliza a garantia dos direitos sociais como uma tecnologia política, uma Biopolítica, que transforma a experiência de população em experiência de cidadania, como elemento de um Estado, de uma sociedade civil. A relação paradoxal entre direitos e mercado econômico, de acordo com Foucault (2004), resolve-se com a criação de um novo objeto de ação governamental: a sociedade civil, noção entendida como tecnologia governamental - uma tecnologia que deve ajustar-se juridicamente a uma economia como processo de produção e intercâmbio. A sociedade civil traz a possibilidade de auto limitação que não rompe a exigência nem das leis da economia, nem das leis do direito, tampouco a necessidade de onipresença do governo. Ela permite ao governo administrar o social, ao mesmo tempo em que não se dissocia do Homo aconomicus, formando um conjunto de tecnologias governamentais (Foucault, 2004).

A sociedade civil garante uma síntese espontânea dos indivíduos; permite, portanto, prescindir do contrato explícito, da renúncia dos direitos, ou seja, não será necessário construir a soberania a partir de um pacto de sujeição. Ela realizará essa renúncia do contrato social pela adição das satisfações individuais no mesmo laço social, isto é, utilizará o mesmo mecanismo de multiplicação imediata da dinâmica econômica dos interesses. Ela formará conjuntos do mesmo nível que agruparão os indivíduos em uma série de núcleos, em comunidades (Foucault, 2004).

Diante disso, é no nível das instituições e das regras de direito que ocorre a regulação social. Nas regras de direito, pela teoria do direito, que se intervêm a fim de instaurar uma ordem social economicamente regulada com base na economia de mercado. Isso significa que o Estado somente pode intervir na economia por meio de princípios formais já que pode assim intervir em um campo constituído por sujeitos econômicos. Ou seja, não é o Estado quem deve dizer que quer aumentar o consumo em tal âmbito, ele deve dizer o que as pessoas podem ou não fazer. Se deve funcionar sempre com leis fixas e predefinidas a priori, nunca mudando de acordo com os efeitos, tanto para o Estado quanto para os indivíduos, a economia deve ser um jogo (Foucault, 2004).

Nesse raciocínio, os modos de governo da vida neoliberais se aproximam de nosso campo de pesquisa no momento em que nos faz visualizar que a ideia de aplicação da lógica jurídico-econômica a todo o tecido social, constitutiva da economia política neoliberal, pode ser um elemento importante para pensarmos os processos de internação compulsória e as políticas públicas de saúde mental. Esse conceito descreve que o governo deve regular, mas deve ter um limite em seu governamento para que o mercado econômico possa operar livremente. Assim, o Estado oferece as ferramentas à população, economiza suas ações limitadoras, objetivando enriquecer a si mesmo através de uma sociedade supostamente livre, que mantêm a governamentalidade operando (Foucault, 2004).

As leis, especialmente as que regem as políticas de saúde mental e as que determinam condições para efetivação da internação compulsória, passam a ser compreendidas neste texto como princípios formais que, através de suas regulações jurídicas, instauram uma determinada proposta de ordem social e de regulação do cotidiano (Reis, 2012). O jogo que se institui nessa trama funciona a partir de leis fixas e predefinidas a priori, que regulamentam o cotidiano das cenas que se formam e das conexões que se estabelecem. O mercado econômico, princípio potente em intervir na ótica de suas próprias necessidades, é tomado por nós como um dos analisadores centrais ao nos aproximarmos dos processos de internação compulsória. Os analisadores são tomados, a partir de uma perspectiva foucaultiana, não como elementos de análise que buscam revelar verdades sobre determinado objeto, mas como questões que potencializam o exercício do pensamento no processo do pesquisar.

Assim, a partir das análises da primeira etapa da pesquisa, visualizamos o contexto dos adolescentes internados por medida compulsória entendendo que o conceito de Biopolítica pode ser um caminho potente para desnaturalizarmos as ferramentas de Estado que estão ali colocadas, assim como os atravessamentos das necessidades de mercado que operam. O Sistema Único de Saúde (SUS), o Hospital Psiquiátrico, a unidade de internação para crianças e adolescentes, os profissionais do serviço, a Classificação Internacional de Doenças (CID), as ofertas de "tratamento" e possibilidades de encaminhamentos passam a ser tomados como ferramentas 
de gestão, oferecidas dentro de determinada lógica de governo (Scisleski \& Maraschin, 2008). Essas ferramentas, ao serem operadas pelas próprias pessoas que compõem sua existência, colocam o adolescente usuário de droga em um processo de cuidado que o destinará a determinados percursos.

Ao analisarmos todo o processo de internação percebemos que a compulsoriedade do "tratamento" tem efeito significativo para tornar a existência de muitos dos jovens produtivas. $\mathrm{O}$ adolescente advém de um contexto de miséria, em que ele não tinha acesso a direitos, bens e serviços. Ao ser inserido em um serviço de saúde mental para crianças e adolescentes sob a justificativa de proteção a sua vida ele passa a fazer operar toda uma rede de serviços, profissionais e insumos que, através de regimes de verdades, utilizam-se do jovem para permanecer existindo e sendo economicamente producentes. Diante disso, o sentido econômico não se constitui diretamente na renda que poderá produzir o jovem ao término da internação, pois como pudemos acompanhar, poucos são os planos de alta que direcionam o jovem a voltar a estudar ou a participar de projetos profissionalizantes. A rentabilidade está nos próprios procedimentos de inserção do jovem na rede de atendimento psiquiátrico que fazem a rede econômica circular. Muitos dos jovens saem do serviço para o mesmo contexto de miséria, a proteção a sua vida, inicialmente ofertada na entrada do serviço, torna-se questionável quando visualizamos pela análise dos documentos de alta que as principais propostas de encaminhamentos para seu futuro se resumem ao consumo de medicações (97\%), encaminhamentos para os serviços de saúde mental (62\%) e sugerindo, de certa forma, novos modos de internação, só que agora em fazendas ou comunidades terapêuticas (26\%).

A maioria dos adolescentes se originam de contextos de miséria e, ao acessarem o serviço, são tomados por profissionais imersos nos universais que circundam suas realidades. Pobreza, falta de higiene, uso de drogas, a inexistência de uma família nuclear, a moradia na rua, a liberdade de circulação na cidade que esse modo de vida possui e a menor idade produzem efeitos que imediatamente colocam os profissionais do serviço em uma autorresponsabilização sobre o abrigamento desses jovens (Reis, 2012). Como nos relataram os profissionais que trabalham no local, muitas vezes eles não sabem o que fazer frente à miséria em que os jovens vivem e abrigá-los se torna a única forma de possibilitar a eles acesso à higiene, alimentação e à estabilidade de uma moradia temporária.
Através dessa análise não estamos aqui culpabilizando esses profissionais que arduamente se esforçam para oferecer o que lhes parece ser a melhor saída frente aos desafios cotidianos dos serviços, mas buscamos sim apontar as supostas ambivalências que são inerentes ao contexto brasileiro de racionalidade neoliberal. Essa racionalidade intervém nos fenômenos populacionais a partir da prerrogativa da garantia de direitos, no entanto, ocorre direcionada a um campo povoado por sujeitos econômicos. Assim, ao mesmo tempo em que o sistema jurídico funda o sujeito de direitos, sujeito por excelência do contrato social que teria constitucionalmente o direito de proteção à vida; o mercado, a partir da perspectiva neoliberal, funda o Homo ofconomicus, sujeito do interesse, do jogo de interesses egoístas que acontecem em função da não ação direta do Estado sobre a economia (Foucault, 2004).

Nesta suposta ambivalência, o resultado é que a sociedade, na situação em análise, obtém um jovem que torna-se vulnerável àquilo que o mercado econômico oferece. O Estado, nessa conjuntura, passa a obedecer às consequências oriundas das limitações internas que nele estão colocadas através das pessoas que cotidianamente o faz operar. Nesse processo, vemos que as práticas de cuidado acabam direcionando os adolescentes para determinados percursos de vida regidos conforme as necessidades econômicas e não conforme a efetivação de direitos constitucionais. Esses percursos tornam suas existências produtivas no momento em que as insere em determinados setores de movimentação de capital. Setores esses que vendem seus serviços amparados pelo argumento do cuidado.

\section{Considerações finais}

A discussão aqui apresentada sobre o processo de internação compulsória de adolescentes usuários de drogas teve como ponto de partida os resultados obtidos na primeira etapa de nossa pesquisa que mapeou o processo de internação, desde a entrada do jovem no serviço, até sua alta. Em seguida, apresentamos a segunda etapa da pesquisa na qual analisamos o processo de internação compulsória tomando a Biopolítica como condutora de nosso pensamento. Essa ação efetuou-se através da perspectiva foucaultiana, buscando colocar em questão os regimes de verdade que legitimam a internação de jovens usuários de drogas em um serviço de saúde mental.

Junto a isso, objetivamos colocar em discussão os possíveis efeitos das racionalidades que configuram as práticas em torno dos sujeitos e de que forma elas 
direcionam os percursos existenciais dos adolescentes após todo processo de internação. O conceito de Biopolítica surge como uma ferramenta teórica que nos permite ampliar nossa visão sobre o campo estudado, permitindo produzir outras reflexões e possibilidades.

Assim, os materiais analisados apontam que, na atualidade, a internação compulsória se coloca como uma medida para sujeitos que advém de situações de rua, abandono, pobreza e marginalização. O diagnóstico psiquiátrico obtido para que o jovem tenha acesso ao serviço, como uma categoria de classificação, marca no real o que não existia a priori e, através do processo de internação compulsória, passa a administrar a vida de muitos dos adolescentes sob mecanismos de investimento que buscam a produção de determinados modos neoliberais de circulação social. Estes passam a ser visibilizados através da inscrição do jovem na rede de serviços de saúde mental, nas comunidades terapêuticas e na prática de consumo de medicações. Vinculações essas que orientam o cotidiano dos adolescentes após a alta do serviço, tornando economicamente produtivas suas existências, para aqueles setores que cotidianamente se mantêm amparados por propostas de cuidado.

Por fim, através da desnaturalização dos universais vinculados a temática aqui em questão, a saber: a criminalização do uso de drogas, os discursos de controle e vigília sobre a população adolescente (especialmente aos pobres e moradores de rua), o discurso impositivo sobre determinadas formas de configuração familiar e sobre modos de higiene, comportamento e valores surgem como rachaduras para que outras possibilidades sejam pensadas. Assim, acreditamos que é apenas suspendendo esses elementos universais, e tomando eles como não existentes ou como não necessariamente as únicas diretrizes para se administrar vidas, que poderemos romper com padrões de cuidado até então colocados.

\section{Referências}

Aragaki, S. S. (2006). O aprisionamento de selves em diagnósticos psiquiátricos (Tese de Doutorado). Recuperado de http://www.sapientia. pucsp.br//tde_busca/arquivo.php?codArquivo=2895

Câmara dos Deputados. (2014). Projeto de Lei PL 7663/2010. Autor: OsmarTerra - PMDB/RS. Recuperado de 2014, de http://www.camara. gov.br/proposicoesWeb/fichadetramitacao?idProposicao $=483808$
Conselho Federal de Psicologia - CFP. (2013). Parecer do Conselho Federal de Psicologia (CFP) sobre o Projeto de Lei no 7663/2010. Brasília, DF. Recuperado de 2014, de http://site.cfp.org.br/wp-content/uploads/2013/03/Parecer-Conselho-Federal-de-Psicologia-PL-7663-2010.pdf

Constituição da República Federativa do Brasil de 1988 (1988, 5 de outubro). Recuperado de http://www.planalto.gov.br/ccivil_03/constituicao/constituicao.htm

Foucault, M. (1984). História da Sexualidade 2: o uso dos prazeres. Rio de Janeiro: Graal.

Foucault, M. (2004). Nascimento da Biopolítica. Curso dado no Collège de France (1978-1979). São Paulo, SP: Editora Martins Fontes.

Foucault, M. (2005). Em defesa da sociedade. Curso no Collège de France (1975-1976). (M. E. Galvão, Trad.) São Paulo: Martins Fontes.

Foucault, M. (2007). História da Sexualidade 1: a vontade de saber. (18르 ed.; M. T. C. Albuquerque, Trad.). Rio de Janeiro: Edições Graal.

Foucault, M. (2008). Segurança, território, população. Curso dado no Collège de France (1977-1978). (E. Brandão, Trad.). São Paulo, SP: Martins Fontes.

Guareschi, N. M. F; Ecker, D. D; Souza, F. M; Galarca, L. G. (2015). Saúde Mental e Justiça: Internação, Tratamento e Alta de Adolescentes Usuários de Drogas. In: A. Scisleski, N. M. F. Guareschi (Orgs.), Juventude, Marginalidade Social e Direitos Humanos: da Psicologia as Políticas Públicas. 1ed. Rio de Janeiro: Vozes.

Guerra ao crack - um talk show para mobilizar o Estado (2009, 30 de junho). Zero Hora, p. 33.

Lei no 8.069, de 13 de julho de 1990. (1990, 13 de julho). Dispõe sobre o Estatuto da Criança e do Adolescente e dá outras providências. Diário Oficial da União, seção 1. Recuperado de http://www. planalto. gov.br/ccivil_03/leis/l8069.htm

Lei ํo 10.216, de 6 de abril de 2001. (2001, 6 de abril). Dispõe sobre a proteção e os direitos das pessoas portadoras de transtornos mentais e redireciona o modelo assistencial em saúde mental. Diário Oficial da União, seção 1. Recuperado de http://www.planalto.gov. br/ccivil_03/leis/leis_2001//10216.htm

Organização Mundial da Saúde [OMS]. (2003). CID-10: Classificação estatística internacional de doenças e problemas relacionados à saúde ( $9^{\underline{a}}$ ed.) São Paulo: EDUSP.

Reis, C. dos. (2012). (Falência Familiar) + (Uso de Drogas) = Risco e periculosidade. A naturalização jurídica e psicológica de jovens com medida de internação compulsória (Dissertação de Mestrado). Universidade Federal do Rio Grande do Sul, Porto Alegre, RS. Recuperado de http://hdl.handle.net/10183/60735

Scisleski, A., \& Maraschin, C. (2008). Internação psiquiátrica e ordem judicial: saberes e poderes sobre adolescentes usuários de drogas ilícitas. Psicologia em Estudo, 13(3), 457-465. doi: 10.1590/S141373722008000300006

Scisleski, A. C. C., Reis, C., Hadler, O., Weigert, M. A. B., \& Guareschi, N. M. F. (2012). Juventude e pobreza: a construção de sujeitos potencialmente perigosos. Arquivos Brasileiros de Psicologia, 64, 19-34. Recuperado de http://pepsic.bvsalud.org/pdf/arbp/v64n3/ v64n3a03.pdf 
${ }_{1}^{1}$ Pesquisa financiada pelo Edital Universal MCTI/CNPq no 14/2012 coordenada pela Prof ${ }^{a}$ Dr ${ }^{\text {a }}$ Neuza Maria de Fátima Guareschi.

${ }^{2}$ O Serviço aqui referido é o Centro Integrado de Atenção Psicossocial - Infância e Adolescência (CIAPS) - atende diversas especificidades vinculadas a transtornos mentais. Único serviço da região que oferece a modalidade de internação para usuários da zona metropolitana e do interior do Estado do RS.

${ }^{3}$ O Hospital Psiquiátrico São Pedro (HPSP) de Porto Alegre, fundado em 13 de maio de 1874, é referência para 88 municípios da região metropolitana (aproximadamente cinco milhões de pessoas). Esse atendimento se dá através de suas sete unidades: 1) Unidade para dependência química; 2) Unidades para pacientes agudos; 3) Centro Integrado de Atenção Psicossocial - Infância e Adolescência (CIAPS); 4) Serviço de emergências psiquiátricas; 5) Unidade de observação;6) Centro de Reabilitação;7) Ambulatório especializado em saúde mental, com programas de atendimento para as principais patologias mentais (Secretaria Estadual da Saúde, 2014).

${ }^{4}$ Livro de baixa é o nome utilizado pelos funcionários do serviço para descrever o caderno de registro no qual se anotam os dados dos usuários que ingressam no serviço.

${ }^{5}$ Mantemos a palavra tratamento entre aspas para enfatizarmos nossas indagações sobre: Tratamento do que? Para quem? Com qual objetivo? Sob qual ponto de vista?

Neuza Maria de Fátima Guareschi, Doutora em Educação pela University of Wisconsin-Madison (1998), Pós-doutorado no Institute of Education na University College of London (2014), é Bolsista Produtividade em Pesquisa CNPq, Coordenadora do Núcleo e-politics - Estudos em Políticas e Tecnologias Contemporâneas de Subjetivação e Professora Adjunta do Programa de Pós-Graduação em Psicologia Social e Institucional (PPGPSI) do Instituto de Psicologia da Universidade Federal do Rio Grande do Sul (UFRGS). Endereço para correspondência: Endereço:

Rua General Souza Doca, №: 270, apto. 301. Bairro: Petrópolis.

CEP: 90630-050, Porto Alegre - RS E-mail: nmguares@gmail.com

Lutiane de Lara, Doutora pelo Programa de Pós-Graduação em Psicologia Social e Institucional (PPGPSI) do Instituto de Psicologia da Universidade Federal do Rio Grande do Sul (UFRGS), é Professora do Curso de Psicologia do Centro Universitário Metodista/IPA. E-mail: lutianelara@gmail.com

Daniel Dall'Igna Ecker, Mestre pelo Programa de Pós-Graduação em Psicologia Social e Institucional (PPGPSI) do Instituto de Psicologia da Universidade Federal do Rio Grande do Sul (UFRGS), é Doutorando no Programa de Pós-Graduação em Psicologia Social e Institucional (PPGPSI) do Instituto de Psicologia da Universidade Federal do Rio Grande do Sul (UFRGS). E-mail: daniel.ecker@hotmail.com 